\title{
ROLE OF UTERINE ARTERY DOPPLER AS A PREDICTOR OF PREECLAMPSIA
}

\author{
Shirish Shanbag ${ }^{1}$, Jyotsna Deshmukh², Tejashree Chandrakant Shelar ${ }^{3}$
}

${ }_{1}^{1}$ Professor, Department of Obstetrics and Gynaecology, RCSM Government Medical College and CPR Hospital, Kolhapur, Maharashtra. ${ }^{2}$ Associate Professor, Department of Obstetrics and Gynaecology, RCSM Government Medical College and CPR Hospital, Kolhapur, Maharashtra.

${ }^{3}$ Speciality Medical Officer, Department of Obstetrics and Gynaecology, RCSM Government Medical College and CPR Hospital, Kolhapur, Maharashtra.

\section{ABSTRACT}

AIM

To study the role of uterine artery Doppler at 11 to 14 weeks as a predictor of preeclampsia.

\section{SETTINGS AND DESIGN}

This study has been conducted at Chhatrapati Pramila Raje Hospital and RCSM Government Medical College, Kolhapur, Maharashtra, which is a tertiary care centre. Duration of the study conducted was one year. Pregnant women attending antenatal OPD's who were willing to participate in the study were included.

\section{METHODS}

This is a prospective study. Total 250 antenatal patients were included. These patients were offered ultrasound examination at 11 to 14 weeks of gestational period. Left and right uterine artery was examined by colour and pulsed Doppler. Mean Pulsatility Index and presence of diastolic notch if any was noted. These patients were followed for occurrence of preeclampsia or any other complication. Pregnancy outcome in both the group was studied. Risk ratio was calculated.

\section{STATISTICAL ANALYSIS}

Pearson's Chi Square test or Fisher's exact test is used to study categoric variables and unpaired ' $t$ ' test is used for studying continuous variables. Thus normal and abnormal Doppler results with incidences of preeclampsia and its complications were studied. Abnormal results in terms of more than $95^{\text {th }}$ percentile of pulsatility in sex and presence of bilateral uterine notch noted. Risk ratio were calculated.

\section{RESULT}

In $96 \%$ of the patients, satisfactory uterine artery Doppler waveform was noted. All the patients were followed till date of delivery to study pregnancy outcome and occurrence of preeclampsia or related complications if any; $95^{\text {th }}$ centile of mean pulsatility index obtained was 2.35 which is constant with gestational age. Patients with abnormal uterine artery Doppler at 11-14 weeks had more incidences of preeclampsia (RR-3.5), intrauterine growth restriction (RR-3) and related complications (RR-5.8) than patients with normal Doppler.

\section{CONCLUSION}

Our study noted that the patients with preeclampsia and associated complications had uterine artery Doppler changes in ultrasound study done at 11 to 14 weeks. So we conclude that the Doppler study done at earlier gestational age is useful in predicting preeclampsia in later gestational period.

\section{KEYWORDS}

Uterine Artery Doppler Preeclampsia Predictor.

HOW TO CITE THIS ARTICLE: Shanbag S, Deshmukh J, Shelar TC. Role of uterine artery doppler as a predictor of preeclampsia. J. Evolution Med. Dent. Sci. 2016;5(23):1261-1264, DOI: 10.14260/jemds/2016/294

\section{INTRODUCTION}

One of the important reasons behind most of the maternal and neonatal morbidity as well as mortality is preeclampsia and complications associated with it.(1,2) Abnormal placentation being aetiology for the same. Normally during placental development, trophoblastic invasion occurs in two phases. First phase at 8 to 12 weeks where there is trophoblastic invasion up to intradecidual portion of the spiral artery.

Financial or Other, Competing Interest: None.

Submission 19-01-2016, Peer Review 02-03-2016,

Acceptance 07-03-2016, Published 21-03-2016.

Corresponding Author:

Dr. Tejashree Chandrakant Shelar,

Akar Bungalow, Rajshree Shahu Colony,

Main Road, Kasba Bawda,

Kolhapur-416006

E-mail: tejarokiya@gmail.com

DOI: $10.14260 /$ jemds/2016/294
Second phase commences from 14 weeks with deeper myometrial trophoblastic invasion. This placental remodelling is completed by $16-18$ weeks underlying basic pathophysiology of preeclampsia is failure of endovascular trophoblastic migration. $(3,4)$ Normally because of invasion of the endovascular trophoblasts into walls of spiral arterioles of uteroplacental bed, there is replacement of endothelial lining and muscular arterial wall by fibrinoid formation. This physiological change transforms uteroplacental vasculature from high resistance into low resistance low pressure system. In preeclampsia as there is failure of endovascular trophoblastic migration together with endothelial dysfunction and vasospasm, there is high resistance flow in the uterofetoplacental unit. This lead to placental hypoperfusion and reduction in the blood supply. $(5,6,7,8)$

Doppler ultrasound is a non-invasive method for examining uteroplacental circulation. There are ample 
evidences, which suggests role of uterine artery Doppler in second trimester as a predictor of developing preeclampsia and associated complications. $(9,10,11)$ But if investigations done in early gestational period can predict further complications well in advance, then preventive measures and monitoring can be started more effectively since early gestational period.

By which we can reduce burden of raised morbidity associated with the same. There are studies carried out to predict preeclampsia and associated complications in late first trimester or early second trimester.

Uterine artery Doppler study at 11-14 weeks can promise this early prediction. $(12,13,14,15)$ With this background we have studied significance of the Doppler study in early pregnancy in predicting the risk of preeclampsia.

\section{MATERIALS AND METHOD}

This study is done at RCSM Government Medical College and Chhatrapati Pramila Raje Hospital, Kolhapur, over a period of 12 months. Women attending routine antenatal clinic were counselled and offered Doppler ultrasound at 11 to 14 weeks of gestation. Written informed consent obtained. Rules and regulations of PCPNDT act were followed. Women placed in supine position and transabdominal ultrasound was performed, so as to get sagittal view of uterus and cervical canal. Internal os of the cervix was first noted, then uterine artery was located by tilting the probe sideways and with the help of Doppler colour flow mapping.(15) Three consecutive wave forms were obtained and pulsatility index was noted. Mean pulsatility index, resistance index was obtained from right and left uterine arteries. Presence of any diastolic notch was noted.

Gestational age calculated by last menstrual date and confirmed by crown rump length. Characteristics of patients like maternal age, significant past history, family history and any risk factor for developing hypertension were noted. These patients were followed till delivery to study their pregnancy outcome.

Outcomes were measured in terms of presence or absence of preeclampsia, intrauterine growth restriction or any complications associated with it.

Preeclampsia is defined as raised blood pressure above $140 / 90 \mathrm{mmHg}$ post 20 weeks in previously normotensive patient with at least two readings $6 \mathrm{hrs}$. Apart with proteinuria more than or equal to $300 \mathrm{mg}$ per $24 \mathrm{hrs}$. or more than ++ in midstream urine sample.(8) This definition is as per international society of study of hypertension in pregnancy. Foetal growth restriction is defined as less than tenth centile of the normal birth weight in the local population. Gestational age at delivery calculated using last menstrual date and first trimester gestational age by CRL. Complications associated with preeclampsia studied in this study are placental abruption, eclampsia, impending eclampsia, intrauterine death.

\section{Inclusion Criteria}

All pregnant women registered for antenatal care irrespective of parity who are willing to participate in the study.

\section{Exclusion Criteria}

Patients with congenital anomalies or chromosomal abnormalities.
Patients on low dose aspirin or heparin as prophylactic measures. Patients with known hypertension with antihypertensive drugs prior to pregnancy.

\section{STATISTICS}

Pearson's Chi Square test or Fisher's exact test is used to study categoric variables and unpaired ' $t$ ' test is used for studying continuous variables. Thus normal and abnormal Doppler results with incidences of preeclampsia and its complications were studied. Abnormal results in terms of more than $95^{\text {th }}$ percentile of pulsatility in sex and presence of bilateral uterine notch noted. Risk ratios for the occurrence of preeclampsia, IUGR, complications were calculated.

\section{RESULT}

Total 250 antenatal patients were included in this study, out of which 6 patients had miscarriage, 4 patients had termination of pregnancy because of congenital anomalies, 8 patients got lost for followup. Pregnancy outcome in remaining 232 patients were studied.

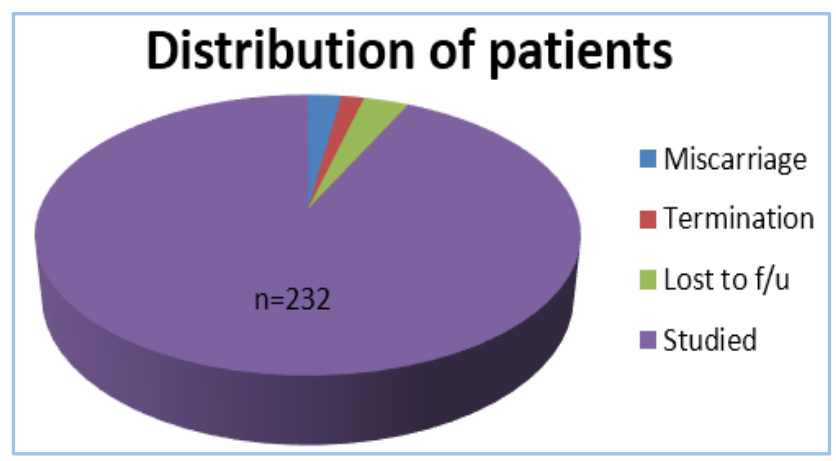

Fig. 1: Distribution of Patients

Of these 232 patients in 96\% (223) of patients satisfactory Doppler with three uniform wave form was obtained, mean pulsatility index was calculated. Of all the studied patients, patients who had normal (128) Doppler findings; $8 \%$ of the patients developed preeclampsia (10), $6 \%$ had IUGR (8) (without preeclampsia), 2.6\% developed severe preeclampsia complications like abruption, eclampsia, impending eclampsia, intrauterine demise, renal failure, DIC (5). Amongst patients with abnormal Doppler findings (95), $28 \%$ had preeclampsia (47), $20 \%$ had IUGR (17), $15 \%$ developed severe preeclampsia complications (15) which is statistically significant $(\mathrm{P}$ value $<0.05)$. Risk ratio was calculated according to which patients with abnormal Doppler reports were three and a half times at risk of preeclampsia, two times at risk of associated severe complications and three times at risk of IUGR.

\begin{tabular}{|c|c|}
\hline Maternal Age (Mean) & 24 years \\
\hline Primi Gravida (Percentage) & $54 \%$ \\
\hline Gestational Diabetes Mellitus & $3.2 \%$ \\
\hline Multiple Gestation & $5.2 \%$ \\
\hline Body Mass Index (Median) & 18.2 \\
\hline Obesity (Percentage) & $2.6 \%$ \\
\hline Preeclampsia in Prior Pregnancies & $4 \%$ \\
\hline Connective Tissue Disorder & $0.6 \%$ \\
\hline \multicolumn{2}{|c|}{ Table 1: Demographic Characteristics } \\
and High Risk Factors \\
\hline
\end{tabular}




\begin{tabular}{|c|c|c|}
\hline & $\begin{array}{c}\text { Normal } \\
\text { Doppler }\end{array}$ & $\begin{array}{c}\text { Abnormal } \\
\text { Doppler }\end{array}$ \\
\hline Abruption & 1 & 2 \\
\hline Eclampsia & 1 & 4 \\
\hline Impending Eclampsia & 2 & 3 \\
\hline Intrauterine Demise & 1 & 3 \\
\hline Renal Failure & 0 & 1 \\
\hline $\begin{array}{c}\text { Disseminated Intravascular } \\
\text { Coagulation }\end{array}$ & 0 & 2 \\
\hline \multicolumn{2}{|c|}{ Table 2: Complications in the Patients Studied } \\
\hline
\end{tabular}

Table 2: Complications in the Patients Studied

\begin{tabular}{|c|c|c|c|}
\hline & $\begin{array}{c}\text { Normal } \\
\text { Doppler }\end{array}$ & $\begin{array}{c}\text { Abnormal } \\
\text { Doppler }\end{array}$ & $\begin{array}{c}\text { Risk } \\
\text { Ratio }\end{array}$ \\
\hline Preeclampsia & $8 \%$ & $28 \%$ & 3.5 \\
\hline $\begin{array}{c}\text { Severe } \\
\text { complications }\end{array}$ & $2.6 \%$ & $15 \%$ & 5.8 \\
\hline IUGR & $6 \%$ & $18 \%$ & 3 \\
\hline \multicolumn{4}{|c|}{ Table 3: Risk Ratio } \\
\hline
\end{tabular}

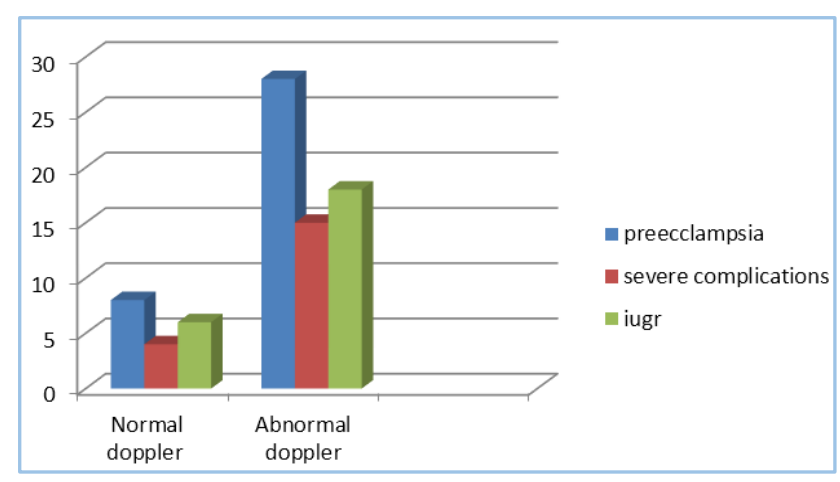

Fig. 2: Bar Diagram showing association of Doppler Findings and Complications

\section{DISCUSSION}

For our Doppler study assessment, we preferred 11-14 weeks' period of gestation as patients are to undergo NT scan and early anatomical assessment during same period in routine followup. We found progressive decrease in resistance index and pulsatility index as increase in gestational period. This finding is consistent with other studies. $(16,17,18)$

Our study demonstrated lower resistance and high velocity flow in normal pregnancies than increased resistance and pulsatility index with pregnancies associated with complications. This reflects there are changes in the uteroplacental circulation in very early stage in pregnancies, which are going to get complicated. With these results we can say abnormal uterine Doppler can predict preeclampsia, IUGR and related complications in later gestational period.

Van Den Elzen et al. in their study found patients with higher uterine artery pulsatility index were associated with two-fold and four-fold increased risk of developing preeclampsia and IUGR respectively.(19,20) similarly our study demonstrated three and a half and three-fold increase in risk in developing preeclampsia and IUGR. Our study has results which are comparable with one of the largest study of Martin et al. ${ }^{14}$

It has been studied that placental ischemia and infarcts, which is a result of defective placentation is the basis behind severe form of early onset preeclampsia or IUGR. But this is not true for patients presenting with less severe late onset near term hypertensive disorder, which is more because of maternal risk factors and not raised uteroplacental resistance.

This group has risk factors, which lead to atherosclerotic changes that take place in normally developed uteroplacental circulation. This theory lead to concept that uterine Doppler changes together with maternal high risk factors will lead to group of patients, which will present with severe forms of hypertensive disorders of pregnancy.(21) Therefore maternal predisposing factors should be combined with abnormal or normal uterine Doppler changes. Therefore, uterine Doppler changes would be useful in predicting only those cases with severe placental ischemia from early stages of pregnancy.

In summary our study suggests there is role of uterine artery Doppler in predicting high risk for preeclampsia and related complications.

\section{CONCLUSION}

It is necessary to identify group of high risk population in early stage of pregnancy. Our study concludes that Doppler study done at earlier gestational period (11-14 weeks of gestation) is useful in predicting adverse pregnancy outcomes. Earlier the risk is known, effective monitoring and prophylactic measures can be started from early gestational age.

\section{REFERENCES}

1. World Health Organization. Make Every Mother and Child Count. World Health Report, Geneva, 2005.

2. Confidential Enquiry into Maternal and Child Health (CEMACH). Perinatal mortality 2006: England, Wales and Northern Ireland. CEMACH: London, 2008.

3. American College of Obstetricians and Gynecologists Committee on Practice Bulletins-Obstetrics. ACOG practice bulletin: diagnosis and management of preeclampsia and eclampsia: number 33. Int J Obstet Gynecol 2002;99(1):159-167.

4. Pijnenborg R, Anthony J, Davey A. Placental bed spiral arteries in the hypertensive disorders of pregnancy. Br J Obstet Gynaecol 1991;98:648-655.

5. Wallace AE, Whitley GS, Thilaganathan B, et al. Decidual natural killer cell receptor expression is altered in pregnancies with impaired vascular remodeling and a higher risk of pre-eclampsia. Journal of Leukocyte Biology 2015;97(1):79-86.

6. Brosens I, Pijnenborg R, Vercruysse L, et al. The 'great obstetrical syndromes' are associated with disorders of deep placentation. American Journal of Obstetrics and Gynecology 2011;204(3):193-201.

7. Khong TY, De Wolf F, Robertson WB, et al. Inadequate maternal vascular response to placentation in pregnancies complicated by pre-eclampsia and by small-for-gestational age infants. Br J Obstet Gynaecol 1986;93:1049 59.

8. Meekins JW, Pijnenborg R, Hanssens M, et al. A study of placental bed spiral arteries and trophoblastic invasion in normal and severe pre-eclamptic pregnancies. Br J Obstet Gynaecol 1994;101:669-674.

9. Davey DA, MacGillivray I. The classification and definition of the hypertensive disorders of pregnancy. Am J Obstet Gynecol 1988;158:892-898.

10. Jacobson SL, Imhof $\mathrm{R}$, Manning $\mathrm{N}$, et al. The value of doppler assessment of the uteroplacental circulation in predicting pre-eclampsia or intra-uterine growth retardation. Am J Obstet Gynecol 1990;162:110- 14. 
11. Bewley S, Cooper D, Campbell S. Doppler investigation of uteroplacental blood flow resistance in the second trimester: a screening study for pre-eclampsia and intrauterine growth retardation. $\mathrm{Br} \quad \mathrm{J}$ Obstet Gynaecol 1991;98(9):871-9.

12. North RA, Ferrier C, Long D, et al. Uterine artery doppler flow velocity waveforms in the second trimester for the prediction of pre-eclampsia and fetal growth retardation. Obstet Gynecol 1994;83:378-86.

13. Plasencia $W$, Maiz N, Bonino S, et al, Uterine artery doppler at $11+0$ to $13+6$ weeks in the prediction of preeclampsia. Ultrasound Obstet Gynecol 2007;30:742-749.

14. Martin AM, Bindra R, Curcio P, et al. Screening for preeclampsia and fetal growth restriction by uterine artery doppler at 11-14 weeks of gestation. Ultrasound Obstet Gynecol 2001;18:583-586.

15. Kaminopetros P, Higueras MT, Nicolaides KH. Doppler study of uterine artery blood flow: comparison of findings in the first and second trimesters of pregnancy. Fetal Diagn Ther 1991;6:58-64.
16. Plasencia W, Barber MA, Alvarez EE, et al. Comparative study of transabdominal and transvaginal uterine artery doppler pulsatility indices at $11-13+6$ weeks. Hypertension in Pregnancy 2011;30(4):414-420.

17. Ridding G, Schluter PJ, Hyett JA, et al. Uterine artery pulsatility index assessment at 11-13 weeks' gestation. Fetal Diagnosis \& Therapy 2014;36:299-304.

18. Sciscione AC, Hayes EJ. Uterine artery doppler flow studies in obstetric practice. American Journal of Obstetrics \& Gynecology 2009;201(2):121-126.

19. Van Del Elzen HJ, Cohen-Overbeek TE, Grobbee DE, et al. Early uterine artery doppler velocimetry and outcome of pregnancy in women aged 35 years and older. Ultrasound Obstet Nd Gynaecol 1995;5(5):328-333.

20. Schuchter K, Metzenbeaur M, Hafner E, et al. Uterine artery doppler and placental volume in first trimester in the prediction of pregnancy complications. Ultasound obstet gnyecol 2001;18:590-592.

21. Ness RB, Roberts JM. Heterogenous causes constituting single syndrome of preeclampsia: hypothesis and its implications. Am J obstet gynecol 1996;175:1365-137. 